\title{
Effect of Warm Rolling on the Rolling and Recrystallization Textures of Non-oriented 3\% Si Steel
}

\author{
Seil LEE and Bruno Charles De COOMAN
}

Materials Design Laboratory, Graduate Institute of Ferrous Technology, Pohang University of Science and Technology, San 31 , Hyoja-Dong, Pohang, South Korea.E-mail: decooman@postech.ac.kr

(Received on January 4, 2011; accepted on May 23, 2011)

\begin{abstract}
The effect of warm rolling in the $50^{\circ} \mathrm{C}-300^{\circ} \mathrm{C}$ temperature range on the microstructure, stored energy and crystallographic texture of a 3 mass-\% Si steel was analyzed. Both rolling and annealing texture were significantly affected by warm rolling. Dynamic strain aging (DSA) was observed in the temperature range $150^{\circ} \mathrm{C}-300^{\circ} \mathrm{C}$. The stored energy, $\mathrm{E}_{<\mathrm{hkl}>}^{\mathrm{S}}$, of $\left\langle\mathrm{hkl}>\| \mathrm{ND}\right.$ oriented grains in the steel warm rolled at $200^{\circ} \mathrm{C}$ was found to decrease in the following order: $E_{<111>}^{S}>E_{<110>}^{S}>>E_{<100>}^{S} \geq E_{<112>}^{S}$. A pronounced $\{110\}<001>$ recrystallization annealing texture was observed in specimens warm rolled in the DSA temperature range. The effect is due to the formation of $\{110\}<001>$ oriented nuclei in deformation bands occurring in $<110>\|$ ND oriented grains after warm rolling. The deformation bands are believed to be caused by the strain localization associated with dynamic strain ageing.
\end{abstract}

KEY WORDS: warm rolling; electrical steel; texture; GOSS orientation; stored energy.

\section{Introduction}

In order to make use of the exceptional magnetic characteristic of iron, an increase of the specific electrical resistance of electrical steels is required to reduce the induced energy loss when the steel is magnetized. $\mathrm{Si}$ is the alloying addition normally used to increase the specific electrical resistance. Additions of $\mathrm{Si}$ in excess of 3.5 mass- $\%$ result in a very limited ductility and the difficulty to process the steel by cold rolling. Crystallographic texture control is essential to obtain low energy losses during magnetization, since the magnetization in an external magnetic field depends on the crystal orientation. Iron is spontaneously magnetized in $<100>$ type directions, and when an external field is applied along one of the $<100>$ cube axis the magnetization increases rapidly to saturation.

Non-oriented electrical steels are used for the rotating motor applications. Thus $<001>$ type easy magnetization directions should be aligned randomly in the plane of the sheet. The crystallographic orientations which have the $<001>$ axis in the rolling plane are the $<100>\|$ ND fiber components, which includes the $\{100\}<001>$ or 'cube' orientation and the $\{100\}<011>$ or the 'rotated cube' orientation. In the case of grain-oriented silicon steels, a high volume fraction of GOSS orientation which has the $<100>$ axis parallel to rolling direction after a primary recrystallization is the main focus of the strip processing steps. In the present work, the strip was heated up to $200-300^{\circ} \mathrm{C}$ prior to cold rolling to enhance strain localization by dynamic strain ageing (DSA). The dynamic interaction between temporarily halted gliding dislocations and mobile interstitial $\mathrm{C}$ atoms is the mechanism causing the DSA. It is expected that the recrystallization rate will be enhanced in the inhomoge- neously deformed microstructure which contains in-grain shear bands formed as a result of DSA.

The stored energy of deformation is due to the accumulation of dislocations. The stored energy within a grain is highly dependent on the orientation and the orientation dependence of the stored energy affects the recrystallization texture significantly. ${ }^{1,2)}$ In ferritic steels, the high rate of recrystallization of certain grains is usually attributed to their high dislocation density and small dislocation cell sizes. The orientation dependence of the stored energy can be measured quantitatively by the electron backscattering diffraction (EBSD) and the X-ray diffraction line broadening method. There is a direct relation between the energy stored inside a deformed grain and the inhomogeneous lattice strain obtained from the analysis of the diffraction peak broadening. The inhomogeneous elastic deformation of grains due to the presence of dislocations and the reduction of the average grain size causes diffraction peak broadening. In ferritic steels, the stored energy in $<\mathrm{hkl}>\| \mathrm{ND}$-oriented grains, $\mathrm{E}_{<\mathrm{hkl}}^{\mathrm{s}}$, as measured by $\mathrm{X}$-ray diffraction after cold rolling has been reported to depend on the orientation in the following manner [2-5]: $\quad \mathrm{E}_{\{110\}<110>}^{\mathrm{S}}>\mathrm{E}_{<111>}^{\mathrm{S}}>\mathrm{E}_{\{110\}<001>}^{\mathrm{S}}>>$ $\mathrm{E}_{<112>}^{\mathrm{S}}>\mathrm{E}_{<100>}^{\mathrm{S}}$.

The aim of the present contribution was to clarify the influence of the warm deformation temperature on the development of the rolling and recrystallization texture of a non-oriented 3\% Si steel. In addition, the development of microstructures warm rolling was investigated for a non-oriented 3\% Si steel. The rolling textures were compared with the initial textures and the annealing textures, the relation between the stored energy and the texture development was evaluated. 


\section{Experimental Procedure}

The composition of the steel used in the present work was $0.001 \% \mathrm{C}, 3.0 \% \mathrm{Si}, 0.3 \% \mathrm{Mn}, 0.3 \% \mathrm{Al}$ (in mass- $\%$ ). Vacuum induction furnace cast material was hot rolled to $2 \mathrm{~mm}$ thickness. The strip was annealed at $1000^{\circ} \mathrm{C}$ for 5 minutes to obtain a $200 \mu \mathrm{m}$ grain size. High temperature tensile tests were done to determine the DSA temperature range using a Gleeble 3500 thermo-mechanical simulator equipped with an extensometer. The tensile tests were done at strain rates of $5 \times 10^{-2} \mathrm{~s}^{-1}$ and $5 \times 10^{-3} \mathrm{~s}^{-1}$. The ultimate tensile strength was measured in the $20^{\circ} \mathrm{C}-400^{\circ} \mathrm{C}$ temperature range. Warm rolling with a reduction of $5 \%$ to $80 \%$ was carried out at $50^{\circ} \mathrm{C}, 100^{\circ} \mathrm{C}, 150^{\circ} \mathrm{C}, 200^{\circ} \mathrm{C}$ and $300^{\circ} \mathrm{C}$. The specimens were subsequently annealed at $700^{\circ} \mathrm{C}$ for 100 seconds in a salt bath to obtain partially recrystallized microstructures revealing the preferred location for the nucleation of GOSSoriented grains in the microstructure.

The peak broadening data obtained from X-ray diffraction (XRD) analysis was used to calculate the orientation-specific stored energy of the grains. The specimens were electropolished in a solution of $30 \%$ perchloric acid in ethanol in order to remove the deformation layer introduced during the specimen preparation. Four peaks, $\{110\},\{200\},\{211\}$ and $\{222\}$, were selected to measure the orientation-specific stored energy. Figure 1 shows an example for the $\{110\}$ peak line broadening after different rolling reductions in the $20^{\circ} \mathrm{C}-300^{\circ} \mathrm{C}$ temperature range. The peaks were normalized and the full width at the half maximum (FWHM) of the peaks was used as a measure of the peak broadening. The stored energy $\mathrm{E}_{<\mathrm{hkl}>}^{\mathrm{S}}$ was determined using an equation proposed by Stibitz: ${ }^{3)}$

$$
\mathrm{E}_{<\mathrm{hkl}>}^{\mathrm{s}}=\frac{3}{2} \cdot \mathrm{E}_{\mathrm{hkl}} \cdot \frac{1}{1+2 \cdot v_{\mathrm{hkl}}^{2}} \cdot\left(\frac{\Delta \mathrm{d}^{\mathrm{hkl}}}{\mathrm{d}_{0}^{\mathrm{hkl}}}\right)^{2}
$$

With,

$$
\frac{\Delta \mathrm{d}^{\mathrm{hkl}}}{\mathrm{d}_{0}^{\mathrm{hkl}}}=\frac{\sqrt{\mathrm{B}_{\mathrm{r}}^{2}-\mathrm{B}_{\mathrm{a}}^{2}}}{2 \tan \theta_{\mathrm{B}}^{\mathrm{hkl}}}
$$

where $\mathrm{E}_{\mathrm{hkl}}$ is Young's modulus and $v_{\mathrm{hkl}}$ is Poisson's ratio. $\frac{\Delta \mathrm{d}^{\mathrm{hkl}}}{\mathrm{d}_{0}^{\mathrm{hkl}}}$ is a direct measure of the strain for the $\{\mathrm{hkl}\}$ planes.

$\mathrm{B}_{\mathrm{r}}$ and $\mathrm{B}_{\mathrm{a}}$ are the FWHM of the $\{\mathrm{hkl}\}$ peak for the rolled

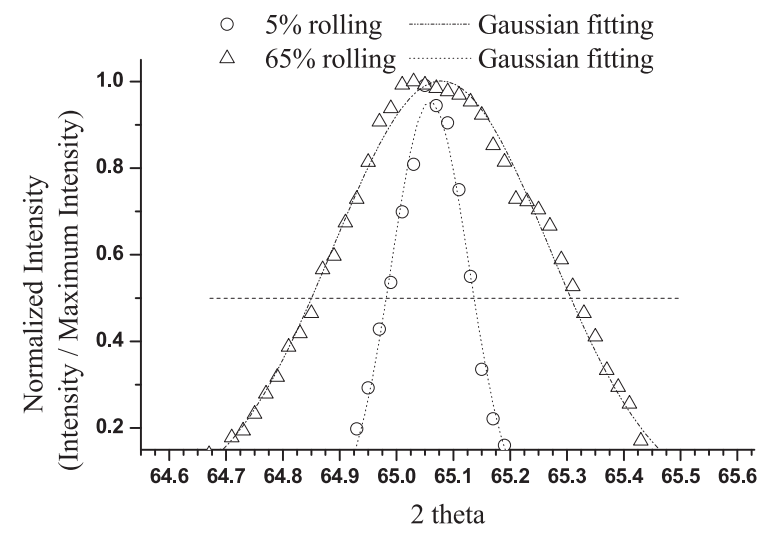

Fig. 1. $\{110\}$ XRD peak profiles for specimens rolled to $5 \%$ and $65 \%$ thickness reduction at $300^{\circ} \mathrm{C}$. The full width half maximum (FWHM) was used as a measure of the peak broadening. and the annealed specimens, respectively. $\theta_{\mathrm{B}}^{\mathrm{hkl}}$ is the Bragg angle. The stored energy was calculated for grains of the following fibers: $<100>\|\mathrm{ND},<112>\| \mathrm{ND},<111>\| \mathrm{ND}$ and $<110>\|$ ND.

The microtexture measurements were carried out on the rolled samples by means of EBSD in a Zeiss Ultra 55 FEGSEM. Orientation imaging microscopy (OIM) was obtained using the software (OIM v.5.0) developed by TexSEM Laboratories. All measurements were performed on the RD-ND plane. The OIM samples were prepared by mechanical polishing with a diamond suspension and final polishing with a colloidal silica suspension. The $65 \%$ warm rolled specimens for the microtexture measurements were chosen to observe the microstructure of the deformed grains with higher resolution by EBSD. When the less amount of deformation was applied on the specimen, the in-grain shear bands were not observed frequently and the more amount of deformation forces to reduce the step size of EBSD measurements and this hinder to observe a relatively large area (at least larger size than several matrix grain size) measurement for achieving a statistical texture data.

\section{Results}

\subsection{Strain Localization in 3\% Non-oriented Si Steel during Warm Deformation}

Figure 2 shows the temperature dependence of the mechanical properties of the $3 \%$ Si steel tested in the $20^{\circ} \mathrm{C}-$ $400^{\circ} \mathrm{C}$ temperature range. Figure 2(a) shows strain versus time curves obtained at different temperatures at the strain rate of $5 \times 10^{-2}$. Serrations, which are a direct indication of the localized deformation associated with dynamic strain

(a)
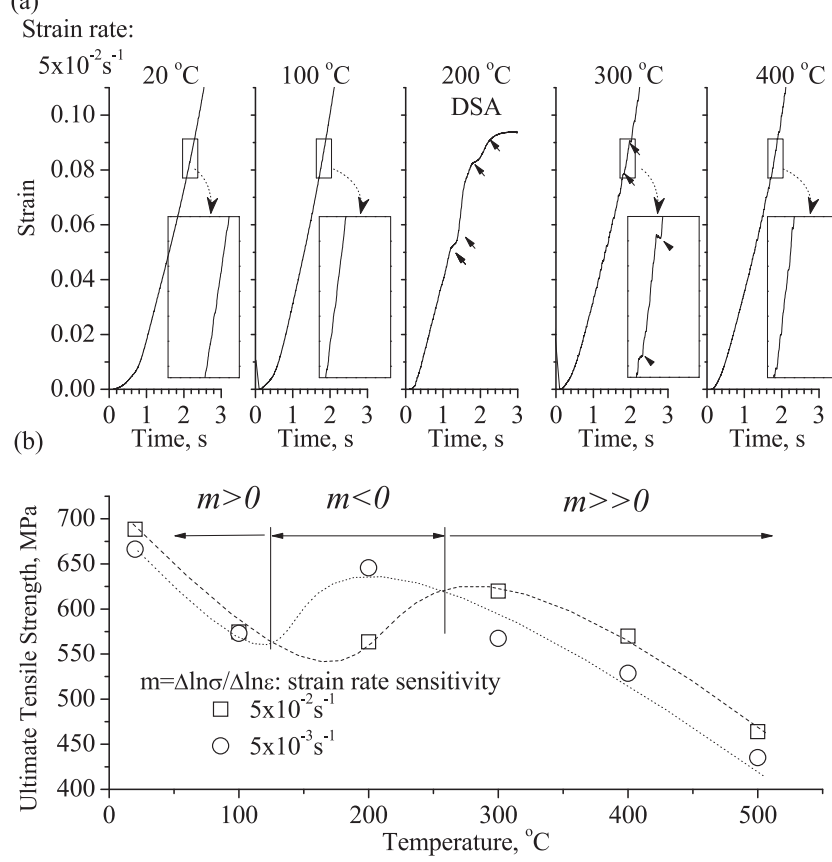

Fig. 2. Mechanical properties of non-oriented 3\% silicon steel in the temperature range $20^{\circ} \mathrm{C}-400^{\circ} \mathrm{C}$, (a) strain-time curves at $\dot{\varepsilon}=5 \times 10^{-2} \mathrm{~s}^{-1}$. The arrows indicate plateaus in the straintime curves are indicative of strain localization due to dynamic strain aging. (b) Temperature dependence of the tensile strength at $\dot{\varepsilon}=5 \times 10^{-3} \mathrm{~s}^{-1}$ and $\dot{\varepsilon}=5 \times 10^{-2} \mathrm{~s}^{-1}$. 
aging, were observed for the tests done at $200^{\circ} \mathrm{C}$. The horizontal segments on the strain-time curve are due to the fact that when the localized deformation zone occurs outside the gauge length of the extensometer, no strain is detected. The localized deformation zones are also known as Portevin-Le chatelier (PLC) bands. Their occurrence has a pronounced effect on the strain rate sensitivity, i.e. they are associated with a negative strain rate sensitivity.

The strain rate sensitivity, $m$ was calculated as follows:

$$
\mathrm{m}=\frac{\ln \sigma_{2}-\ln \sigma_{1}}{\ln \dot{\varepsilon}_{2}-\ln \dot{\varepsilon}_{1}}
$$

In the $150^{\circ} \mathrm{C}-250^{\circ} \mathrm{C}$ temperature range, the ultimate tensile strength measured at a strain rate of $\dot{\varepsilon}=5 \times 10^{-3} \mathrm{~s}^{-1}$ was found to be higher than at a strain rate of $\dot{\varepsilon}=5 \times 10^{-2} \mathrm{~s}^{-1}$. This is a clear indication of negative strain rate sensitivity (Fig. 2(b)). Both the serrations due to strain localization and the negative strain rate sensitivity are indications of the occurrence of dynamic strain aging in the $150^{\circ} \mathrm{C}-250^{\circ} \mathrm{C}$ temperature range although the serration on stress-strain curve of $300^{\circ} \mathrm{C}$ warm rolled sheet was observed with a positive strain rate sensitivity.

\subsection{Stored Energy Measurement}

Figure 3 shows the stored energy of $<110>\|$ ND, $<100>\|$ $\mathrm{ND},<112>\| \mathrm{ND}$ and $<111>\| \mathrm{ND}$ oriented grains as a function of strain at different rolling temperatures. A significant increase of stored energy of grains in the $<110>\|$ ND orientation was observed after 5\% rolling (Fig. 3(a)). The stored energies of $<111>\| \mathrm{ND}$ and $<100>\| \mathrm{ND}$ oriented grains in the $30 \%$ rolled specimen (Fig. 3(b)) were increased considerably by an increase of the rolling temperature. The

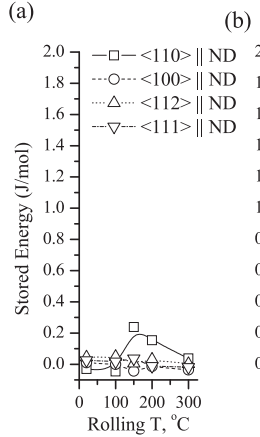

(b)

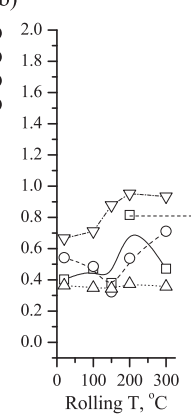

(c)

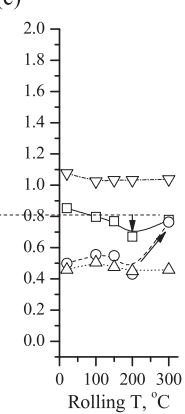

(d)

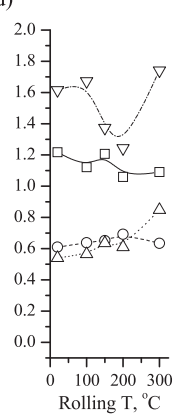

Fig. 3. Stored energy for specific grain orientations as function of warm rolling temperature after (a) 5\% rolling, (b) 30\% rolling, (c) $65 \%$ rolling and (d) $80 \%$ rolling. stored energy of $<110>\| \mathrm{ND}$ and $<100>\| \mathrm{ND}$ oriented grains were significantly changed in the $65 \%$ rolled specimen. The stored energy of $<110>\| \mathrm{ND}$ oriented grains warm rolled $65 \%$ at $200^{\circ} \mathrm{C}$ was lower than the stored energy after $30 \%$ rolling at the same temperature. The stored energy of $<100>\|$ ND oriented grains increased with increasing rolling temperature and it reached a similar level of stored energy as for the $<110>\| N D$ oriented grains. In the specimen rolled at $80 \%$, the stored energy of $<110>\|$ ND and $<111>\|$ ND oriented grains increased significantly.

\subsection{Texture Evolution}

The ODFs of the warm rolled samples which were calculated from the EBSD measurements data are shown in Fig. 4. The observation area of the each EBSD measurements was $0.7 \mathrm{~mm} \times 2 \mathrm{~mm}$. The sample warm rolled at $50^{\circ} \mathrm{C}$ had a texture similar to the crystallographic texture of a cold rolled low carbon steel. ${ }^{4)}$ It had a $\alpha$-fiber $(<110>\| \mathrm{RD})$ and $\gamma$-fiber $(<111>\| \mathrm{ND})$ and the strongest texture component was $\{111\}<112>$. The $\alpha$-fiber extended to $\phi_{1}=20^{\circ}$ from the exact RD $\|<110>$ fiber. In the case of the texture of the $200^{\circ} \mathrm{C}$ warm rolled sample, however only the $\gamma$-fiber was developed and the strongest texture component, $\{111\}<112>$ was broadened towards the $<112>\|$ ND fiber. The texture of the $300^{\circ} \mathrm{C}$ warm rolled sample showed a pronounced $\{223\}<110>$ texture component along $\alpha$-fiber. A $\gamma$ fiber was less strongly developed in the sample.

ND Inverse pole figure maps of ND-RD planes for partially recrystallized samples are shown in Fig. 5. The material was warm rolled to a $65 \%$ reduction at $50^{\circ} \mathrm{C}, 200^{\circ} \mathrm{C}$ and $300^{\circ} \mathrm{C}$ and annealed at $700^{\circ} \mathrm{C}$ for 100 seconds. The texture varied with the rolling temperature. The recrystallized volume fraction of the specimens was also found to vary with their rolling temperatures. The material rolled at $300^{\circ} \mathrm{C}$ was fully recrystallized while the material rolled at $50^{\circ} \mathrm{C}$ was only partially recrystallized. The grains observed in the sample rolled at $50^{\circ} \mathrm{C}$ revealed that the recrystallization of the grains was dependent on their orientation. Recrystallization sites for the $<111>\| \mathrm{ND}$ oriented grains were observed at the initial grain boundaries. GOSS oriented recrystallized grains lying on shear bands were observed for the steel rolled at $200^{\circ} \mathrm{C}$, i.e. in the temperature range where the DSA effect occurs. This is an important observation as it has been reported previously that the shear bands were effective nucleation sites for GOSS $\{110\}<001>$ oriented grains. ${ }^{5,6)}$ The sample rolled at $300^{\circ} \mathrm{C}$ had a Cube orientation as the strongest texture component and a very weak $\gamma$-fiber, $<111>\|$ ND intensity.
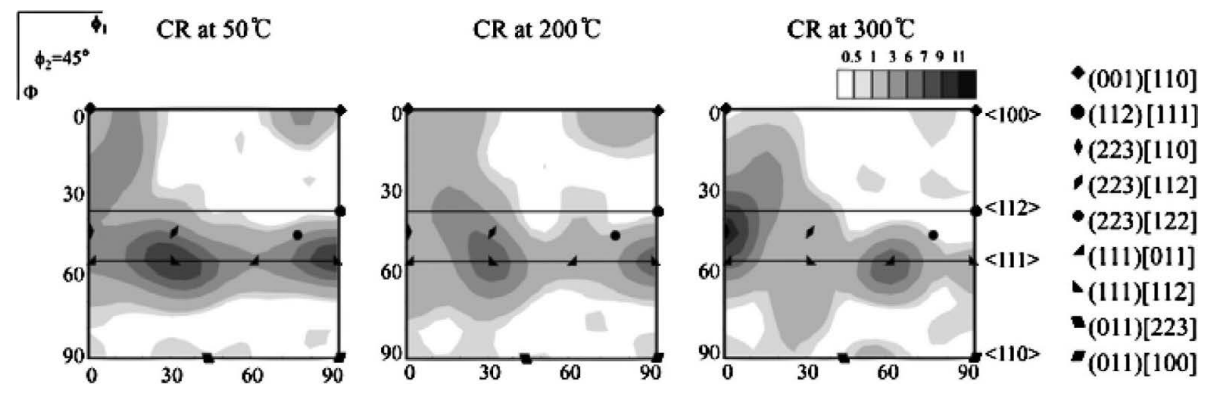

Fig. 4. ODFs for the RD-ND plane of specimens warm-rolled $65 \%$ at $50{ }^{\circ} \mathrm{C}, 200^{\circ} \mathrm{C}$ and $300^{\circ} \mathrm{C}$. 

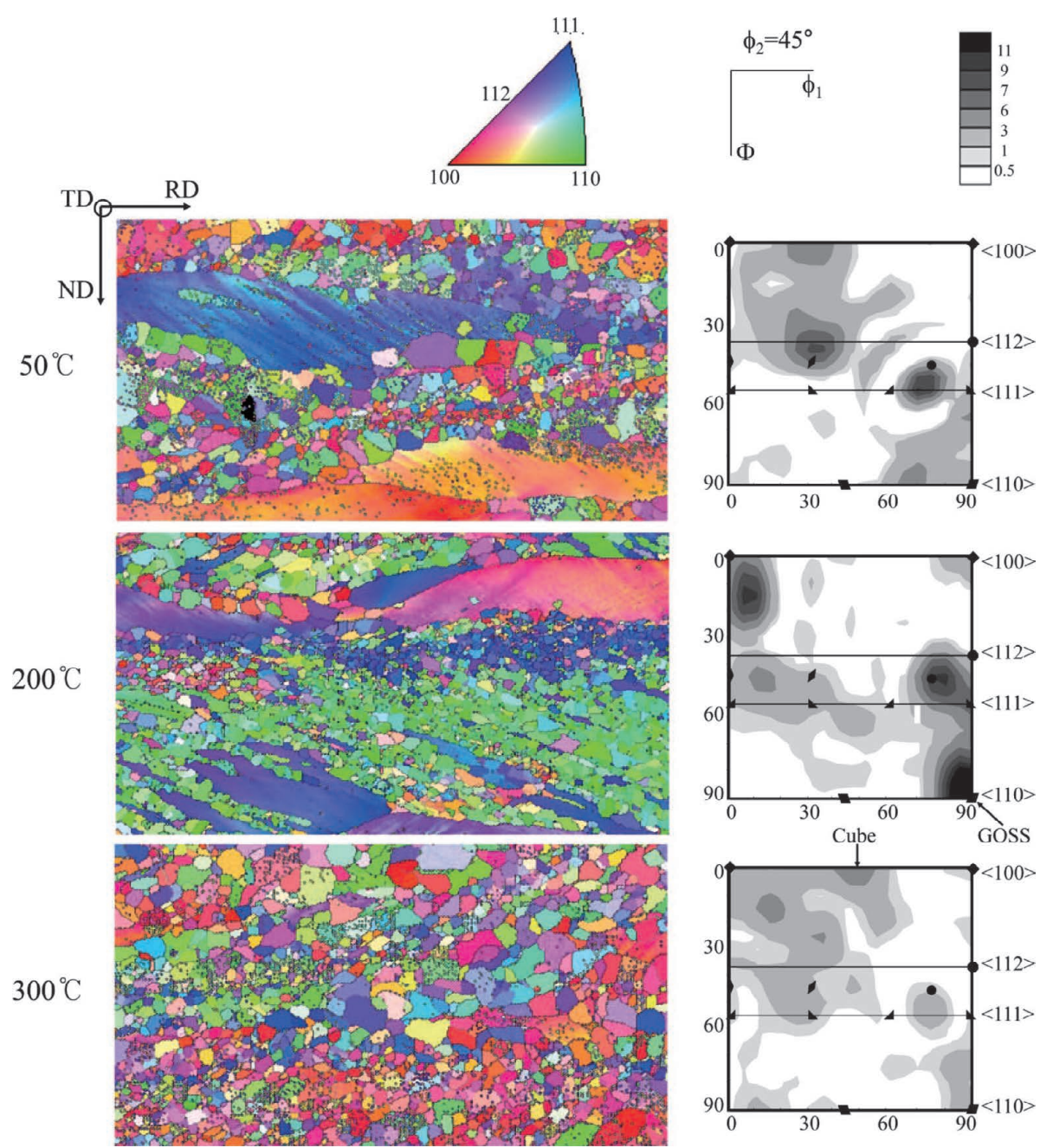

Fig. 5. ND inverse pole figure maps and ODFs for the RD-ND plane of specimens warm-rolled $65 \%$ at $50^{\circ} \mathrm{C}, 200^{\circ} \mathrm{C}$ and $300^{\circ} \mathrm{C}$ and annealed at $700^{\circ} \mathrm{C}$ for $100^{\circ} \mathrm{C}$ seconds.

\section{Discussion}

\subsection{Quantitative Estimation of the Orientation Depen- dent Stored Energy}

The stored energy can be estimated quantitatively by means of the Taylor theory which assumes that the individual grains undergo the same strain as that of the macroscopic sample. The stored energy of a grain with a specific orientation is expected to be directly related to the Taylor factor M. ${ }^{7)}$ The Taylor factor of a grain orientation is equivalent to the amount of slip on an active slip system for a given strain state. The Taylor factor is given by the following general expression:

$$
M=\frac{d \gamma}{d \varepsilon}
$$

A high $\mathrm{M}$ value implies that more dislocations i.e. slip are required to achieve a certain amount of strain. The Taylor factor of a slip system is therefore a rough measure of the work hardening of a grain during a specific deformation. As such the Taylor factor is also related to the stored energy: a high $\mathrm{M}$ value orientation is expected to have a high stored energy after deformation. The main assumption for the determination of the Taylor factor is that the grains are deformed homogeneously independently of the difference of the resistance against their deformation exerted by the surrounding grains. The Taylor factor values calculated for the full constraint model for the plane strain deformation are shown in figures, which can be considered similar to a $\phi_{2}=$ $45^{\circ}$ section of an ODF maps, $\varepsilon_{11}=1, \varepsilon_{22}=0, \varepsilon_{33}=-1$, in Fig. 6(a) and in shear deformation during a rolling, $\varepsilon_{11}=1$, $\varepsilon_{13}=1.45, \varepsilon_{33}=-1$, in Fig. 6(b). Although pure bcc $\alpha$-Fe has multiple $\{110\}<111>,\{112\}<111>$ and $\{123\}<111>$ slip systems, the addition of $\mathrm{Si}$ tends to restrict slip to $\{110\}<111>$-type slip systems. ${ }^{8}$ Only $\{110\}<111>$ slip systems were therefore considered for the Taylor factor represented in Fig. 6. The amount of shear by in-grain shear bands were determined as $\gamma=2.9$ by Ushioda and Hutchinson. ${ }^{9)}$ This result was adapted to calculate the Taylor factor which was represented in Fig. 6(b).

\subsection{GOSS Oriented Grains in $200^{\circ} \mathrm{C}$ Warm Rolled $3 \%$ Si Steel}

The Goss oriented grains were observed in the 3\% Si steel rolled at $200^{\circ} \mathrm{C}$. The material was rolled to a $65 \%$ thickness reduction in the DSA temperature range. Zarubova ${ }^{10)}$ observed a serrated flow curve for a 3\% Si single crystal in the temperature range of $523 \mathrm{~K}-773 \mathrm{~K}$. He reported that the work hardening rate increased with increasing temperature. Cuddy and Leslie ${ }^{11)}$ also reported serrations in the stress- 
(a)

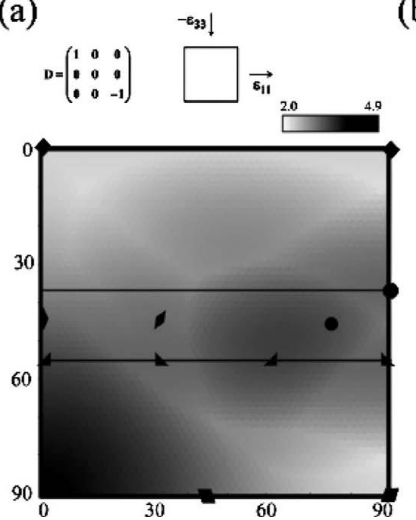

(b)

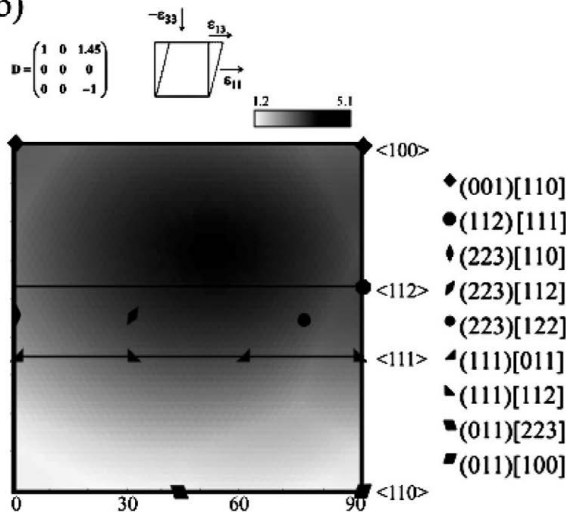

Fig. 6. Taylor factor map in the $\phi_{2}=45^{\circ}$ section of Euler space, (a) in plane strain $\left(\varepsilon_{11}=1, \varepsilon_{22}=0, \varepsilon_{33}=-1\right)$ and (b) in shear rolling deformation $\left(\varepsilon_{11}=1, \varepsilon_{13}=1.45, \varepsilon_{33}=-1\right)$.

strain curve of a $1.5 \% \mathrm{Si}$ steel at $500-775 \mathrm{~K}$. The temperature range for the observation of the serrations was strain rate dependent. Lee et al. ${ }^{12)}$ reported a serrated flow curve at a temperature of $100^{\circ} \mathrm{C}$ when the strain rate was $10^{-3} \mathrm{~s}^{-1}$. The mechanism of the occurrence of DSA has been explained as the diffusion of solute $\mathrm{C}$ from the forest dislocation along the core of the mobile dislocation at a junction of a mobile dislocation temporarily arrested by a forest dislocation. $^{13)}$

In-grain shear bands are the most apparent microstructural feature produced by DSA. In-grain shear bands have a highly localized misorientation. ${ }^{14)}$ The shear bands consist of very thin and elongated cells with a high dislocations density. In-grain shear bands are associated with a localized softening which leads to a local strain concentration. ${ }^{15)}$ The shear band region, having a high density of dislocations, are highly effective nucleation sites for recrystallization. ${ }^{16)}$ According to Jonas et al. ${ }^{17-19)}$ more grains having the $<111>\|$ ND orientation are obtained when more shear bands are present in low carbon steels. Inagaki ${ }^{20,21)}$ reported that shear bands obtained as a result of plastic instability resulted in more grains with a GOSS orientation. Ushioda et al. ${ }^{9)}$ explained the latter observation by the presence of GOSS nuclei inside the shear bands. The GOSS nuclei was found that they were located in the shear bands formed in $\{111\}<112>$ oriented grains.

In order to confirm this, $\{111\}<112>$ oriented grains in $65 \%$ rolled sample were selected from EBSD measurement results from RD-ND sections of $50^{\circ} \mathrm{C}$ and $200^{\circ} \mathrm{C}$ warm rolled samples. The results of the in-grain microtexture evolution by a warm rolling were represented in ODFs which were shown in Figs. 7(b) and 7(d). Also, 588 individual orientations deviating from the exact $\{111\}<112>$ orientation by 7.5 degree were used to simulate the effect of the deformation gradient change on the in-grain microtextural evolution. This calculation was done using the full-constrain Taylor model. The results are shown in Figs. 7(a) and 7(c). Planes strain compression $\left(\varepsilon_{11}=1, \varepsilon_{22}=0, \varepsilon_{33}=-1\right)$ was assumed for Fig. 7(a) and simple shear $\left(\varepsilon_{11}=1, \varepsilon_{13}=1.45\right.$, $\varepsilon_{33}=-1$ ) was assumed for Fig. 7(c). The shear bands regions are usually assumed to be formed by a combination of simple shear and planes strain compression. The thickness strain was 1.0 , corresponding to a $65 \%$ rolling reduction. In the case of the plane strain compression, the $\{111\}<112>$ (a)
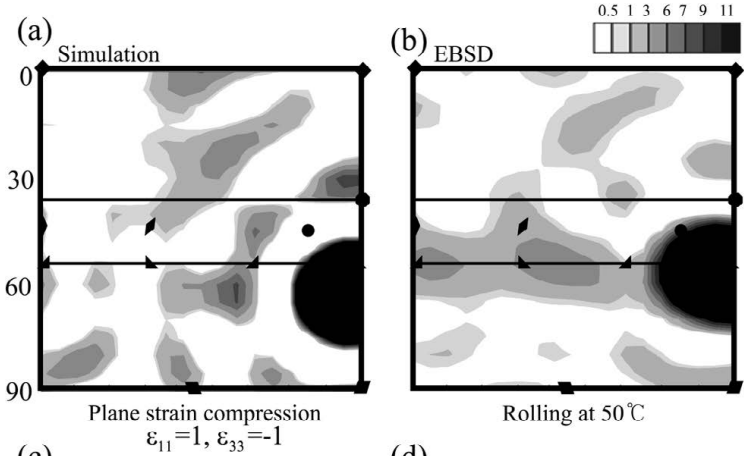

(c) $\varepsilon_{\text {Simulation }}$

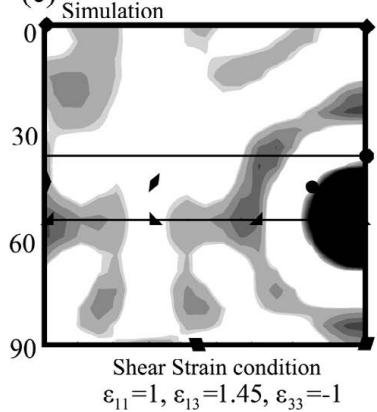

(d) $\mathrm{EBSD}$

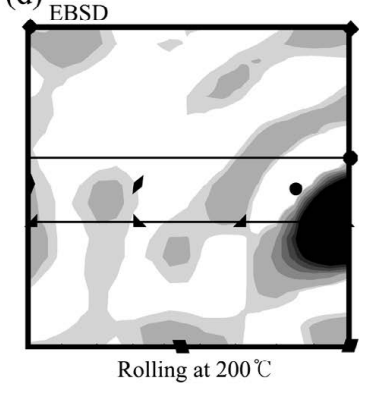

Fig. 7. Simulated textures of $\{111\}<112>$ orientation after (a) plane strain compression and (c) shear rolling and measured textures of $\{111\}<112>$ oriented grains of (b) $50^{\circ} \mathrm{C}$ and (d) $200^{\circ} \mathrm{C}$ warm- rolled samples by EBSD in the $\phi_{2}=45^{\circ}$ section.

orientation was not stable and it rotated toward $\{443\}<338>$. The GOSS orientation did not develop, while the Cube orientation and $\{45,25,45\}$ orientation developed moderately. The $\{111\}<112>$ orientation, however, was stable in the simple shear. The GOSS orientation and the rotated cube orientation were clearly developed. Orientations close to the exact $\{111\}<112>$ orientation did not rotate toward other orientations. The results of the simulation matched to the EBSD observations shown in Figs. 7(b) and $7(\mathrm{~d})$. The $50^{\circ} \mathrm{C}$ rolled sample showed a similar texture evolution by a plane strain and the $200^{\circ} \mathrm{C}$ rolled sample showed similar texture evolution by simple shear. The Taylor factors of orientation in $<110>\|$ ND fiber are small in simple shear during rolling condition (Fig. 6(b)).

The volume fraction of the $<110>\|$ ND fiber orientation in the total volume and the volume fraction of the each texture component belonging to the $<110>\|$ ND fiber orienta- 
tion after a warm rolling within 15 degree misorientation deviation from the exact orientations are shown in the Fig. 8. The volume fraction of $<110>\|$ ND orientation of the

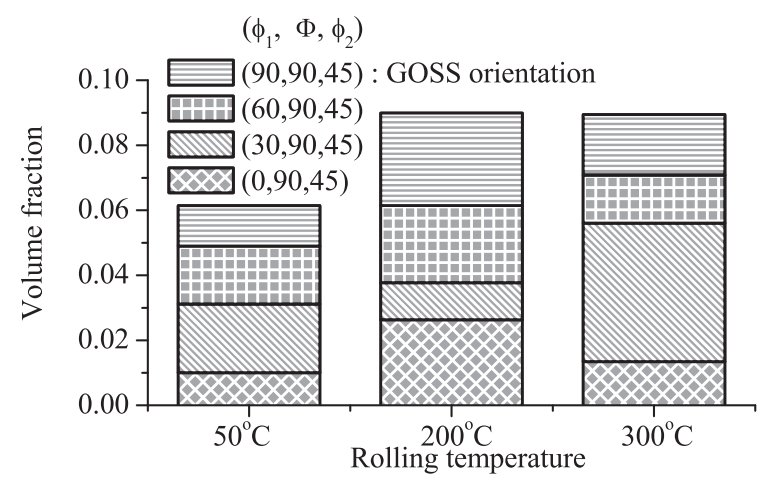

Fig. 8. Volume fractions of the texture components in $\langle 110>\|$ ND fiber orientation (in Euler space, $\Phi=90, \phi_{2}=45$ ), the misorientation deviation is within 15 degree. $200^{\circ} \mathrm{C}$ warm rolled sample was about 1.5 times higher than the $50^{\circ} \mathrm{C}$ rolled sample. The volume fraction of $<110>\| \mathrm{ND}$ orientation of the $200^{\circ} \mathrm{C}$ warm rolled sample is about $9 \%$. The volume fraction of the GOSS orientation in the $200^{\circ} \mathrm{C}$ rolled sample was about $2.85 \%$ and the volume fraction of the GOSS orientation in the $50^{\circ} \mathrm{C}$ rolled sample was about $1.24 \%$. The main texture component in the $<110>\| \mathrm{ND}$ fiber orientation was $(30,90,45)$ in the Euler space in the $50^{\circ} \mathrm{C}$ and the $300^{\circ} \mathrm{C}$ warm rolled samples. The GOSS orientation was the major texture component in the $200^{\circ} \mathrm{C}$ warm rolled sample. This increase of the GOSS orientation intensity resulted from simple shear deformation during rolling at $200^{\circ} \mathrm{C}$.

The decrease of the stored energy, $\mathrm{E}_{\mathrm{s}}^{<110>}$, of the $200^{\circ} \mathrm{C}$ warm rolled sample after a $65 \%$ rolling can now be explained. The GOSS orientation had the lowest Taylor factor value of the $<110>\|$ ND fiber orientation and the Taylor factor value increased to the maximum value with rotation to the $\{110\}<110>$ orientation in the plane strain compression. In the case of simple shear during rolling, however, the

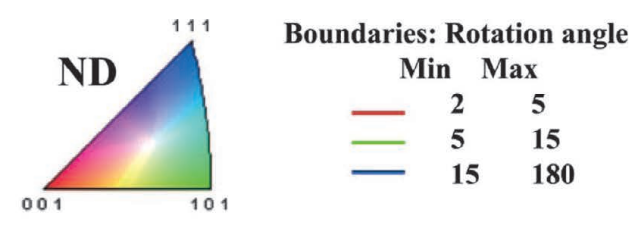

(a)
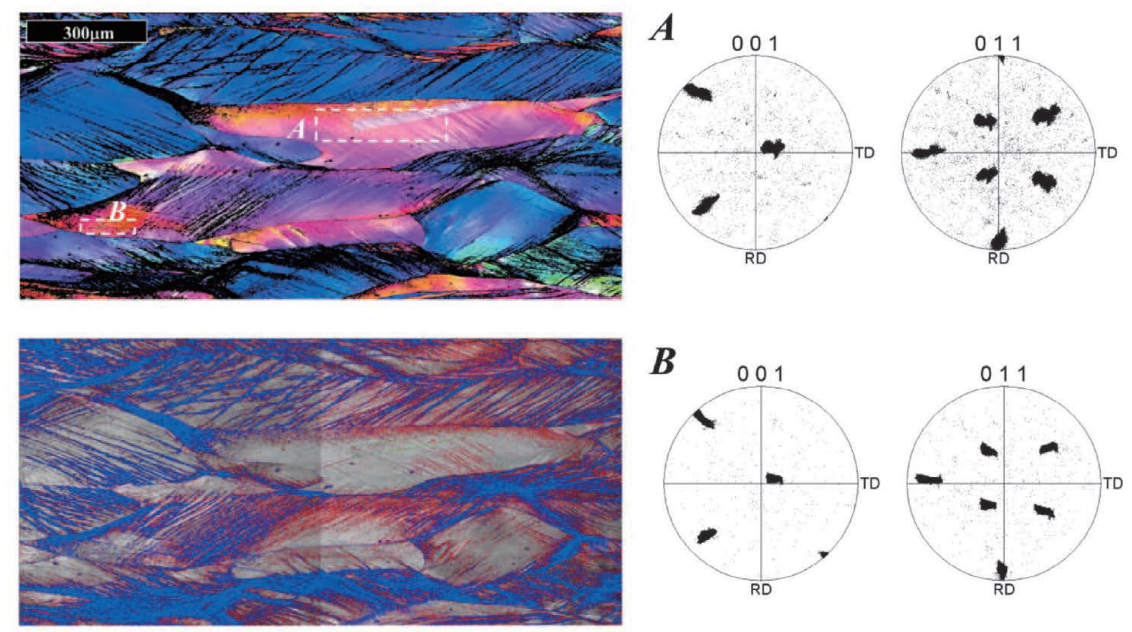

(b)
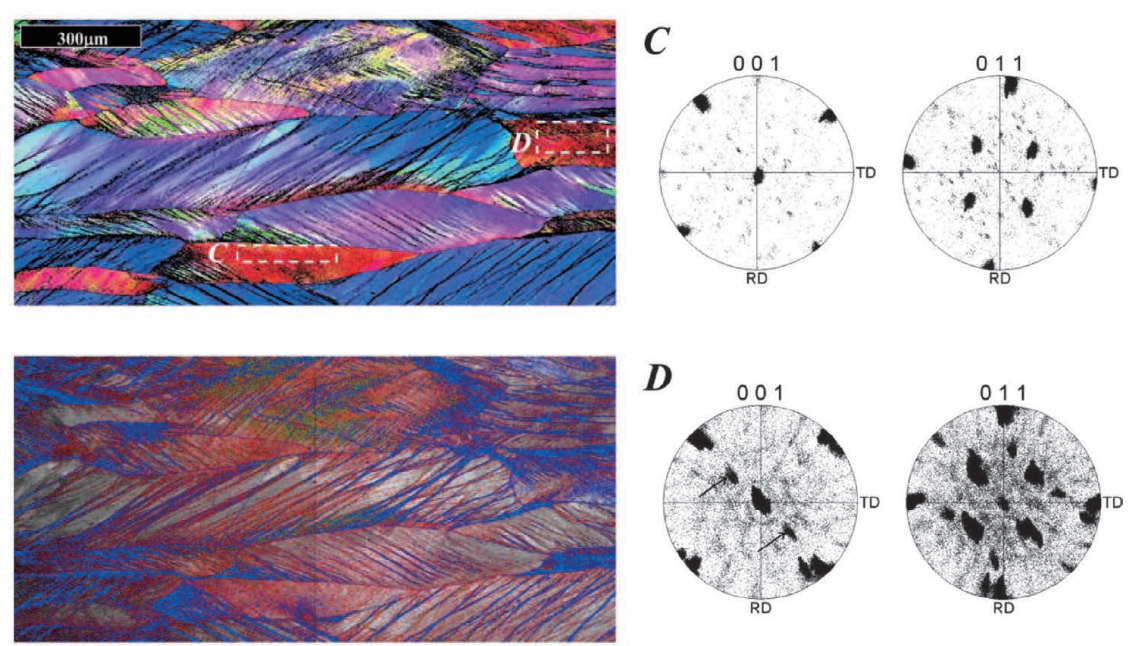

Fig. 9. ND Inverse pole figure maps and image quality maps of two specimens rolled at (a) $50^{\circ} \mathrm{C}$ and (b) $300^{\circ} \mathrm{C}$ in $65 \%$ thickness reduction. $\{001\}$ and $\{011\}$ Pole figures of white area where inside grains oriented to ND $\|<100>$ were represented. 


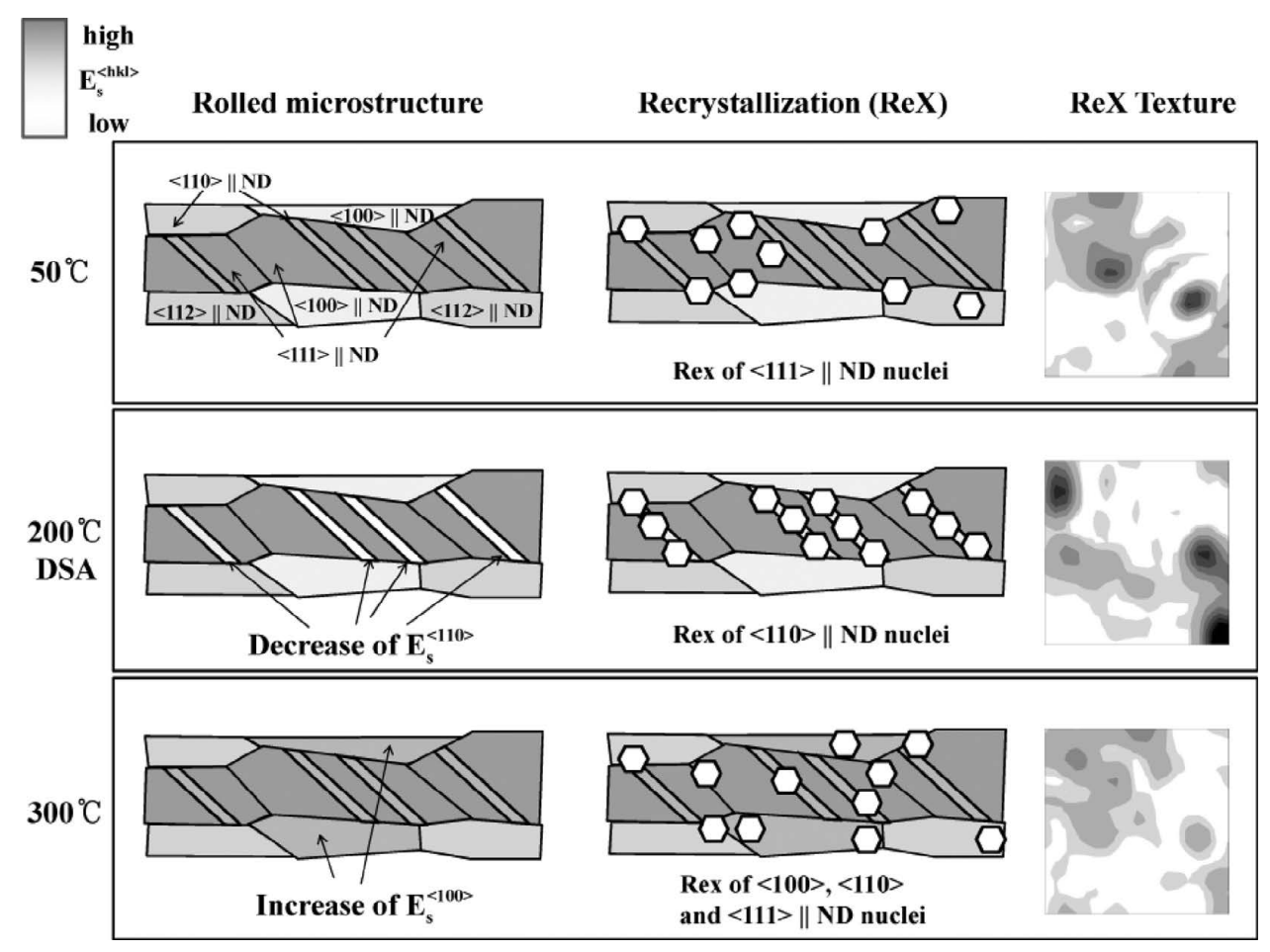

Fig. 10. Effect of the rolling temperatures to the texture evolution during the recrystallization.

calculated Taylor factor value of the $\{110\}<110>$ orientation decreased to a value similar to that of the GOSS orientation. Thus increase of the volume fraction of the GOSS orientation by simple shear deformation during rolling caused the decrease of the stored energy, $\mathrm{E}_{\mathrm{s}}^{<110>}$. The increase of the volume fraction of the GOSS orientation before recrystallization resulted in the increase of the GOSS recrystallized grains during annealing. Due to the higher dislocation densities of the $<111>\|$ ND oriented matrix grains, the GOSS oriented nuclei were readily recrystallized.

\section{3. $<100>\|$ ND Oriented Grains in $300^{\circ} \mathrm{C}$ Warm Rolled 3\% Si Steel}

The $<100>\|$ ND grains have been reported to recrystallize at a later stage of annealing, ${ }^{2}$ due to their low stored energy. However if the driving force for their recrystallization was sufficient, the $<100>\|$ ND oriented grains would survive after recrystallization.

ND Inverse pole figure (IPF) maps and rotation boundaries on image quality maps of ND-RD planes for warm rolled specimens at $50^{\circ} \mathrm{C}$ and $300^{\circ} \mathrm{C}$ are shown in Fig. 9 . The grain boundary identification angle was 5 degree and grain boundaries appeared as a black line on the IPF maps. The shear bands were only observed in the grains which closely oriented to ND $\|<111>$ fiber for a $50^{\circ} \mathrm{C}$ rolled specimen. Shear bands were observed in all area regardless of the orientation of the grains in the $300^{\circ} \mathrm{C}$ rolled specimen. The grains oriented close to the ND $\|<100>$ fiber were selected and $\{001\}$ and $\{011\}$ pole figures for the grains were represented. The data for the $300^{\circ} \mathrm{C}$ rolled specimen was more scattered than in the $50^{\circ} \mathrm{C}$ rolled specimen. Each point on the pole figure represented an orientation of a measured point in the selected region. As higher plastic strain causes the wider scattering points, it is possible to conclude that the grains with a ND $\|<100>$ orientation in a $300^{\circ} \mathrm{C}$ rolled specimen were more deformed. As a result, a higher stored energy was measured for the ND $\|<100>$ fiber oriented grains in a $300^{\circ} \mathrm{C}$ rolled specimen.

The rotation boundaries with a rotation less than 15 degree are usually considered to be low angle boundaries. Fewer low angle boundaries were observed with a ND \| $<100>$ fiber orientation in the $50^{\circ} \mathrm{C}$ rolled specimen. In contrast, high angle boundaries were observed in grains with an orientation close to the ND $\|<100>$ fiber in the $300^{\circ} \mathrm{C}$ rolled specimen. The effect of the rolling temperature are schematically illustrated in Fig. 10. When the rolling is carried out below the DSA temperature range, localized deformation shear bands formation is limited, and the newly recrystallized $<111>\| N D$ oriented grains are located at the grain boundaries. There are no nuclei with other orientations in unrecrystallized $<111>\| N D$ oriented grain and the major texture components after recrystallization belong to the $\gamma$ fiber. The recrystallization of $\langle 100\rangle \|$ ND fiber oriented nuclei is usually retarded. Rolling in the DSA temperature range causes a significant amount of localized deformation and formation of shear bands. The nuclei in the shear bands have orientations close to the GOSS orientation. These grains recrystallize prior to those having other orientations. When the rolling temperature is above $300^{\circ} \mathrm{C}$, ND $\|<100>$ oriented grains are more deformed and this leads to a higher stored energy. These results in a randomized texture after annealing because the ND $\|<100>$ orientated grains do not disappear as a result of grain growth of grain having nucleated at an earlier stage during annealing.

\section{Conclusions}

The effect of the warm rolling temperature on the annealing texture of a non-oriented 3\% Si steel using EBSD analysis was studied. The stored energy dependence on the 
warm rolling temperature was measured by the X-ray peak broadening method and the effect of the stored energy in the rolled state on the annealing texture was studied. The stored energy of the grains was found to depend on the rolling temperature, reduction ratio and their orientations.

When a $65 \%$ warm rolling reduction was applied at $200^{\circ} \mathrm{C}$ in the temperature range for DSA, the volumes fraction of $<110>\|$ ND fiber increased after $65 \%$ warm rolling and especially the volume fraction of grains with the GOSS orientation increased significantly. The annealing texture of this sample processed in this manner had a pronounced GOSS orientation, and the GOSS-oriented recrystallized grains were observed to occur in shear bands.

In the case of warm rolling at $300^{\circ} \mathrm{C}$, the volume fraction of the $<110>\|$ ND fiber was similar to that of the sample rolled in the DSA temperature, but the volume fraction of the GOSS orientation was small. The stored energy of $<100>\|$ ND oriented grains increased and the annealing texture had a more random texture with a larger volume fraction of $<100>\|$ ND oriented grains.

Depending on the warm rolling temperature, various annealing texture were obtained. The textures, i.e. GOSS and ND $\|<100>$ fiber orientations, which are favored for improved magnetic properties could be obtained more easily than in cold rolling.

\section{REFERENCES}

1) Y. B. Park, D. N. Lee and G. Gottstein: Acta Mater., 44 (1996), 3421.

R. L. Every and M. Hatherly: Texture, 1 (1974), 183.

3) G. R. Stibitz: Phys. Rev., 49 (1937), 862.

4) R. K. Ray, J. J. Jonas and R. E. Hook: Int. Mater. Rev., 39 (1994), 129

5) I. Samajdar, B. Verlinden, L. Kestens and P. Van Houtte: Acta Mater., 47 (1998), 55.

6) T. Haratani, W. B. Hutchinson, I. L. Dillamore and P. Bate: Met. Sci., 18 (1984), 57.

7) T. Urabe and J. J. Jonas: ISIJ Int., 34 (1994), 435.

8) D. Hull and D. J. Bacon: Intoduction to Dislocations, Pergamon Press, Oxford, England, (1984).

9) K. Ushioda and W. B. Hutchinson: ISIJ Int., 29 (1989), 862.

10) N. Zarubova: Scr. Metall., 11 (1977), 441.

11) L. J. Cuddy and W. C. Leslie: Acta Metall., 20 (1972), 1157.

12) S. Lee, S. K. Chang and B. C. De Cooman: AIST Steel Properties and Applications Conf. Proc., Combined with Ms and T'07, Materials Science and Technology 2007, Detroit, MI, (2007), 1077.

13) R. A. Mulford and U. F. Kocks: Acta Metall., 27 (1979), 1125.

14) D. Raabe and K. Luecke: Mater. Sci. Forum, 157-6 (1994), 597.

15) W. B. Hutchinson, B. J. Duggan and M. Hatherly: Met. Technol., 6 (1979), 398.

16) B. Hutchinson: in Met. Sci. Forum, Jeju Island, Trans Tech Publications, Switzerland, (2007), 13.

17) A. O. Humphreys, D. Liu, M. R. Toroghinejad, E. Essadiqi and J. J. Jonas: Mater. Sci. Technol., 19 (2003), 709.

18) M. R. Toroghinejad, A. O. Humphreys, D. Liu, F. Ashrafizadeh, A. Najafizadeh and J. J. Jonas: Metall. Trans. A, 34 A (2003), 1163.

19) M. R. Barnett and J. J. Jonas: ISIJ Int., 37 (1997), 706.

20) H. Inagaki: Z. Metallkd., 82 (1990), 265

21) H. Inagaki: ISIJ Int., 34 (1994), 313. 